\title{
LUPUS VULGARIS: - AN UNUSUAL FACIAL INVOLVMENT
}

\author{
Mandakini. B. T, Hakeem. A, Zennath. B
}

1. Assistant Professor, Department of Pathology, KBN Institute of Medical Sciences, Gulbarga.

2. Assistant Professor, Department of Pathology, KBN Institute of Medical Sciences, Gulbarga.

3. Associate Professor, Department of Pathology, KBN Institute of Medical Sciences, Gulbarga.

\section{CORRESPONDING AUTHOR:}

Dr Mandakini. B. Tenglr,

C/O Dr. Srinivas,

H. No. 1-888/1, Shastri Nagar,

Gulbarga- 04, Karnataka,

Email id- attar.hakeem@gmail.com,

Ph- 00919844586236.

\begin{abstract}
:
BACKGROUND: Primary infection with tuberculosis occurs only rarely on the skin. The lesions of Lupus vulgaris are usually found on the head or neck. The skin of and around the nose is frequently involved. But, we report a rare case, where a 36 years' old male patient presented with a Lupus vulgaris lesion over the upper part of the cheek, near the outer canthus of the right eye, of 9 years' duration. Histopathological examination showed granulomatous infiltration, with caseous necrosis. Mantoux test was positive. The lesion showed marked improvement on antituberculous treatment. We want to emphasize that histopathological examination has diagnostic value in Lupus vulgaris.
\end{abstract}

KEYWORDS: Lupus vulgaris, facial skin, granuloma, caseation necrosis.

\section{INTRODUCTION:}

There is a resurgence of tuberculosis everywhere because of a combination of factors including immigration from endemic countries, HIV pandemic, poverty, etc. as a result, tuberculosis remains a clinical and diagnostic problem ${ }^{[1]}$.

Lupus vulgaris is the most common morphological variant of cutaneous tuberculosis accounting for approximately $59 \%$ of cases of cutaneous tuberculosis in India. $[4,6,10]$. Cutaneous tuberculosis forms a small proportion of extrapulmonary tuberculosis [3,7].It has been shown that Lupus vulgaris is the most common form in adults. ${ }^{[3,8]}$.

In India, the sites of predilection are the buttocks and trunk [3,9].

We report a rare case of Lupus vulgaris affecting facial skin.

\section{CASE REPORT:}

A 36 year's old male patient presented with history of a chronic progressive non- healing lesion on the upper part of the right cheek, near the outer canthus of the eye, of 9 year's duration. Clinical examination revealed a well-demarcated, irregularly bordered, reddish-brown patch, containing deep-seated nodules, each about $1 \mathrm{~mm}$. in diameter, with central area of atrophy and scarring (fig-1).

Journal of Evolution of Medical and Dental Sciences/ Volume 1/ Issue 3/ July-Sept 2012 Page 124 
Topical antibacterial, antifungal and steroid ointments were tried earlier, but there was no response.

Clinical diagnosis of Granuloma annulare was made, and Lupus vulgaris was the differential diagnosis. There was no pervious history of tuberculosis, either pulmonary or extrapulmonary. There was no regional lymphadenopathy, and systemic examination showed no abnormalities. There was no similar family history Routine hematological examination revealed lymphocytosis and raised ESR-80mm. Mantoux test was positive. Biochemical investigations like random blood sugar, TB-IgG/IgM (slide method), VDRL, HIV, serum creatinine, and serum urea levels were within normal limits. Chest X-ray was done which showed bronchitis with no evidence suggestive of tuberculosis.

Histopathological study of the punch biopsy from the edge of the lesion revealed normal epidermis, and the dermis showed tuberculoid granulomas consisting of epithelioid histiocytes, Langhans giant cells surrounded by lymphocytes, with slight central caseation necrosis. Tissue sections were negative for Acid fast bacilli.

\section{DISCUSSION:}

Infection of the skin and subcutis by Mycobacterium tuberculosis occurs by three routes;

1) By direct inoculation into the skin.

2) By hematogenous spread from an internal lesion.

3) From an underlying tuberculous lymph node by direct extension (causing scrofuloderma).[1]

Mycobacterium bovis, atypical Mycobacteria and the BCG Vaccine can cause tuberculosis involving the skin [5]. The diagnosis of cutaneous tuberculosis is challenging and requires the correlation of clinical finding with diagnostic testing. ${ }^{[5]}$ The determinants of what happens in tuberculosis infection, includes, the virulence of the organism, the size of the inoculum, the route of infection, and the immune status of the patient. The lesions of Lupus vulgaris are usually found on the head and neck. The lesion in our case was a well-demarcated, reddishbrown patch, containing deep-seated nodules, each about $1 \mathrm{~mm}$ in diameter, with central area of atrophy and scarring. The diagnosis in this case was based on histopathological study of the biopsy of the lesion, which showed typical granulomatous tubercles with epithelioid cells, Langhans giant cells and a mono-nuclear inflammatory infiltrate (fig-3\&4). Caseation necrosis was seen (fig-5) and AFB Negative

The patient was administered antitubercular therapy and the lesion resolved completely in 6 months and 2 year follow-up shows no recurrence. (Fig-2).

Lupus vulgaris is completely curable as has been seen in the present case. The consequences of failing to make an early diagnosis can be disastrous for the patients, as the progression of the disease can lead to necrosis, destruction of bones and cartilage leading to permanent deformity $[4,6,9$, and 10$]$.

The special test like polymerase chain reaction (PCR) for TB can be done to substantiate the diagnosis or wherever the histopathology is inconclusive $[4,6,9$, and 10].

Journal of Evolution of Medical and Dental Sciences/ Volume 1/ Issue 3/ July-Sept 2012 Page 125 


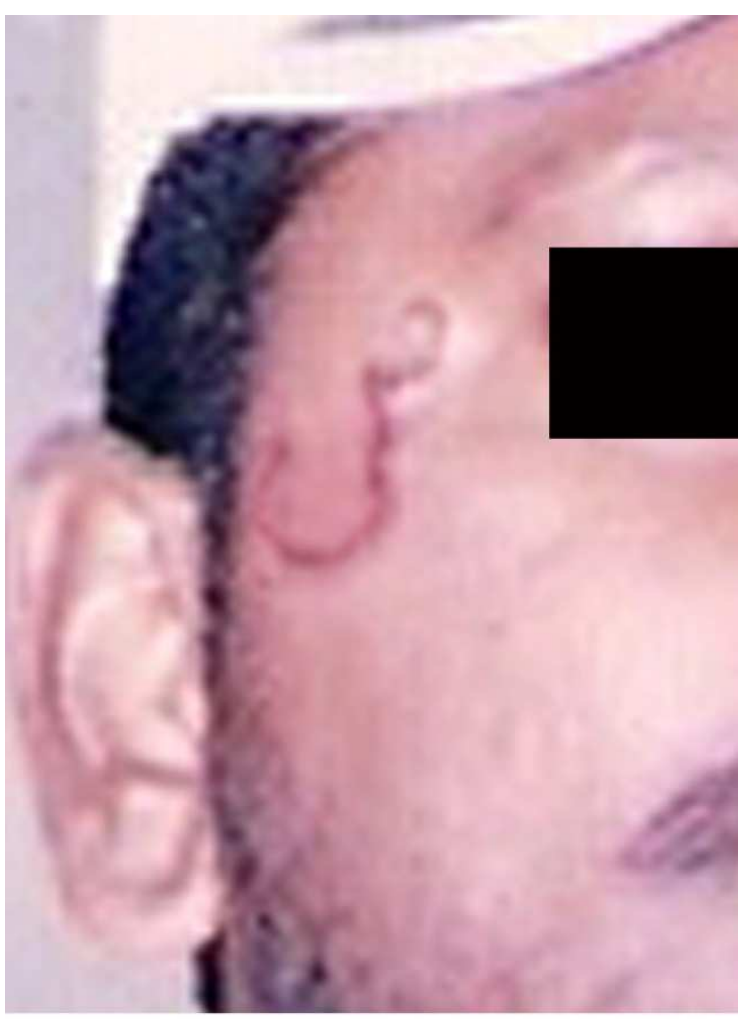

Fig 01

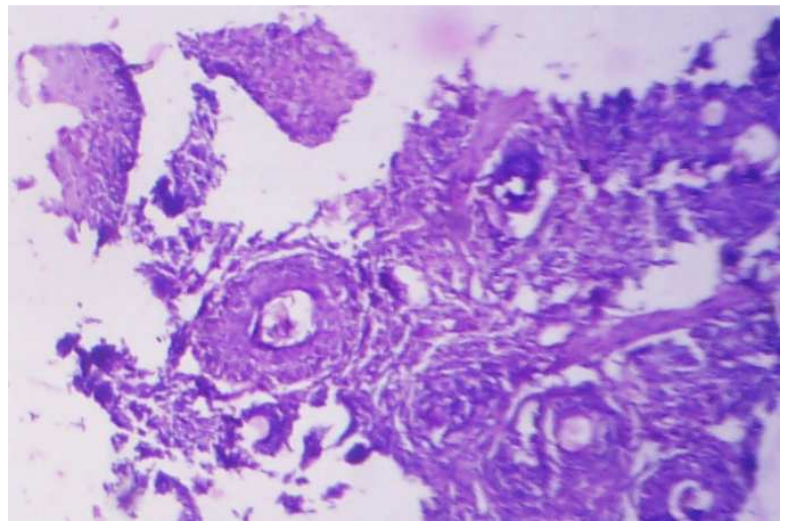

Fig 03

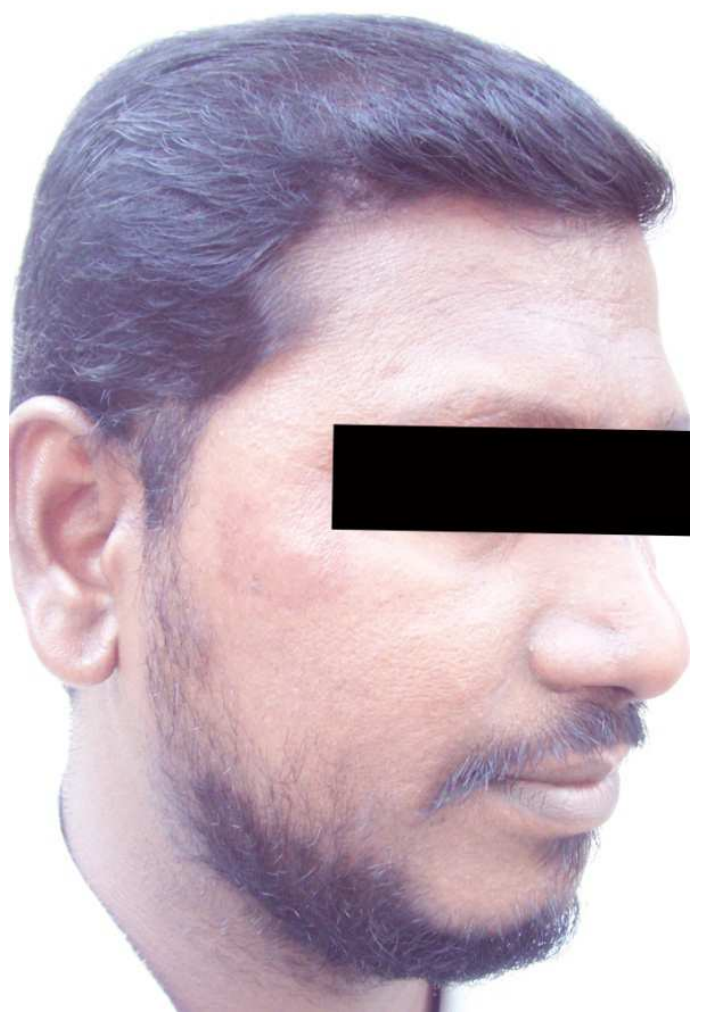

Fig 02

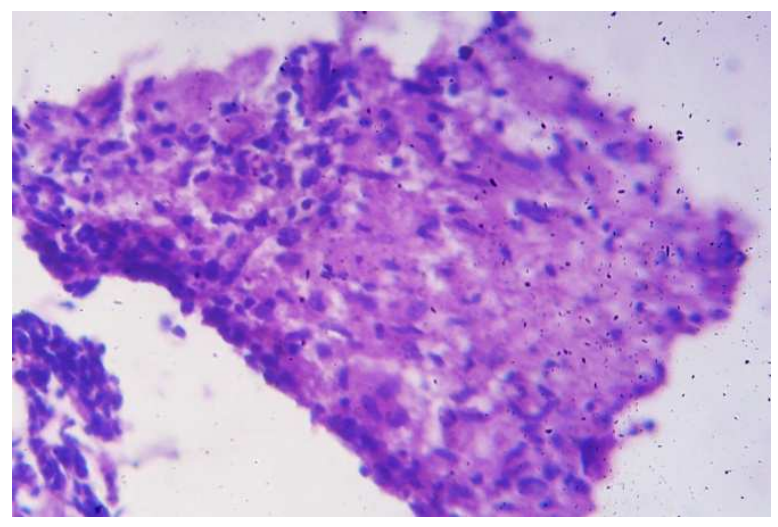

Fig 04

Journal of Evolution of Medical and Dental Sciences/ Volume 1/ Issue 3/ July-Sept 2012 Page 126 


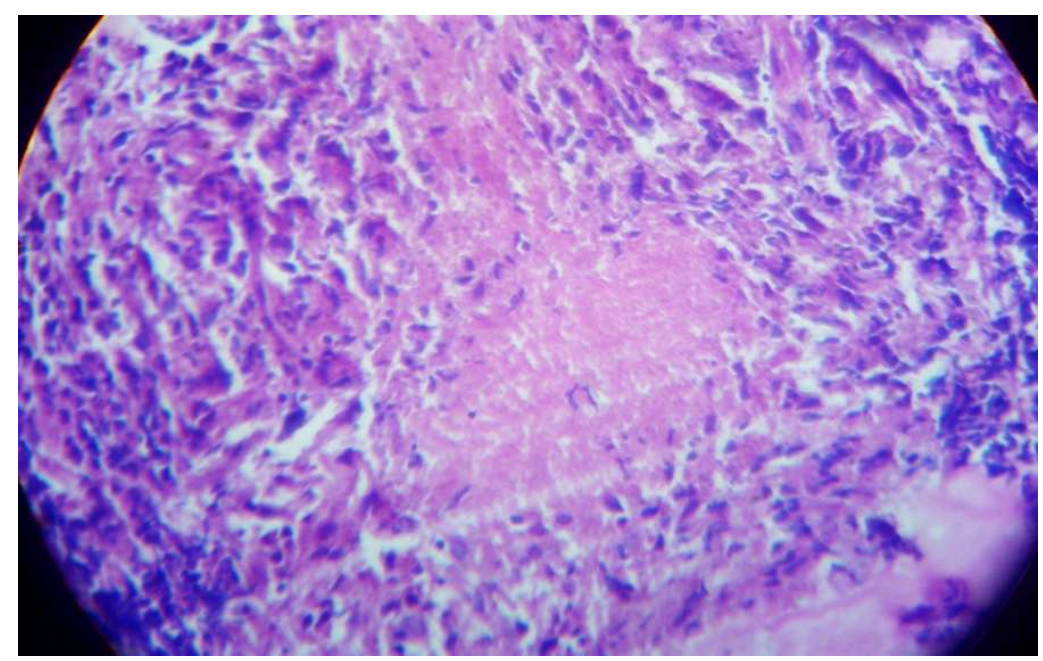

Fig 05

\section{REFERENCES:}

1). Sebastian L. Bacterial Diseases. In: Lever's Histopathology Skin. David E Elder. Lippincott Williams \& Wilkins 9th edition 2005.

2). Afsar SF., et al. Lupus vulgaris in a pediatric patient: a clinicohistopathological diagnosis. Braz J Infect Dis vol. 12 no. 2 Salvador Apr. 2008.

3). Jain, V. K.,et al. Hypertrophic Lupus vulgaris an unusual presentation. Indian J Dermatol 2009: 54(3): 287-9.

4). Chakravarti: A., et al. Lupus vulgaris of external nose. Indian J Tuberc 2006; 53: 220222.

5). Wg Cdr P Kinra, Col S Srinivasan, Col SPV Turlapti, Lt Col A Kumar. Lupus vulgaris with abscess. MJAFI 2009; 65: 84-85.

6). Ramesh V, Misra RS, Jain RK. Secondary tuberculosis of skin: clinical features and problems in laboratory diagnosis. Int J Dermatol 1987; 26: 578-581.

7). Yates VM, Rook GA. Mycobacterial infections In: Burns T, Breathnach S, Cox N, Griffiths C, editors. Rook's Textbook of Dermatology. $7^{\text {th }}$ ed. Oxford. Blackwell Scientific Publications; 2004. p. 28.1-39.

8). Sehgal VN, Wagh SA. Cutaneous tuberculosis Int J Dermatol; 1990: 237-52.

9). Khadim Ullah Kakakhel. Cutaneous Tuberculosis. International Journal of Dermatology 1989; 28: 355-362.

10). S Khandpur, BSN Reddy. Lupus vulgaris: Unusual presentations over the face. Journal of European Academy of Dermatology and Venereology 2003; 17: 706-710. 